\title{
Effect of Cooling Mode on the Performance of a Solar Driven Natural Vacuum Desalination System
}

\author{
M.I. Mahrous, H. Kotb, E.H. Amer and A.R. El-Ghalban \\ Mechanical Power Engineering Department, Faculty of Engineering, \\ Menoufiya University, Shebin El-Kom, EGYPT
}

\begin{abstract}
A solar driven sea water desalination system operating under natural vacuum has been developed, constructed and tested. The system utilizes the natural forces of gravity and atmospheric pressure to create vacuum under which water can be evaporated at temperatures lower than those in conventional techniques and allowing the use of low -grade heat sources. The proposed desalination system consists of a condenser and a solar flat plate collector acting as an evaporator. An extensive experimental study has been carried out to investigate the effect of condenser cooling mode on the system performance. The external surface of the condenser has been cooled by using three cooling modes; namely, free convection air cooling, forced convection air cooling, and forced convection water cooling. The effect of cooling modes on the system performance has been studied under actual weather conditions. The system performance has been characterized by its fresh water productivity and the performance ratio. The results showed that forced cooling mode causes a lower pressure inside the system than free cooling mode, and water cooling is more effective than air cooling. The average pressure inside the system is about $0.122,0.106$, and 0.09 bars absolute respectively for free air cooling, forced air cooling and water cooling. The cumulative productivity is maximum in the case of external water cooled reaching a value of $6.61 / \mathrm{m}^{2}$.day. In case of forced and free air convection, the daily system productivity 5.3 and $2.71 / \mathrm{m}^{2}$.day respectively. The average performance ratio was about $70 \%$ which is twice the value for a conventional solar still reported in the literature.
\end{abstract}

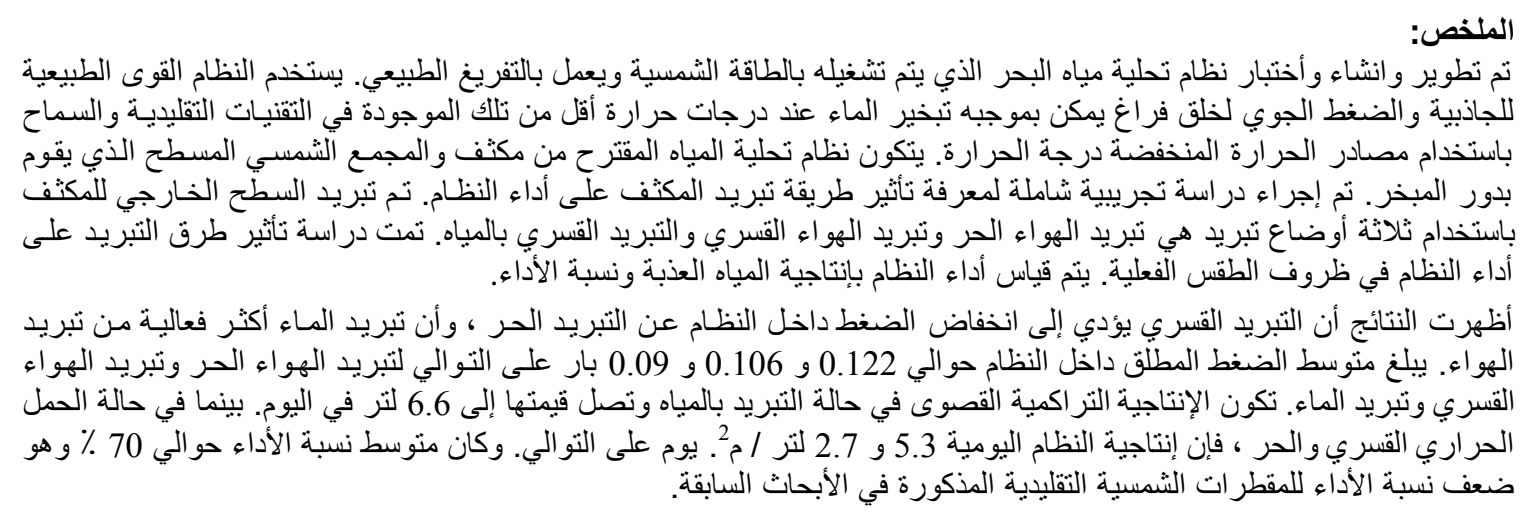

Keywords: system performance, natural vacuum desalination, solar energy, free and forced air cooling, external water cooling.

\section{INTRODUCTION}

Many areas of the world suffer from water scarcity and the inadequate supply of fresh water. Desalination of seawater and/or brackish water is an important alternative, since the only inexhaustible source of water is the ocean. The total amount of global water reserves is about 1.4 billion cubic kilometers. Oceans constitute about $97.5 \%$ of the total amount, and the remaining $2.5 \%$ fresh water is present in the atmosphere, polar ice, and ground water. This means that only about $0.014 \%$ is directly available to human beings and other organisms,
[1]. So, development of new clean water sources is an imperative must.

Desalination processes require significant amount of energy. It was estimated that the production of one million $\mathrm{m}^{3}$ /day requires 10 million tons of oil per year, [2]. Due to high cost of conventional energy sources, which are also environmentally harmful, renewable energy sources (particularly solar energy) have gained more attraction since their use in desalination plants will save conventional energy for other applications, reduce environmental pollution, and provide free, continuous and low maintenance energy source. Many desalination 
systems are powered by low temperature sources. These include thermal desalination and membrane desalination. Recently, desalination systems operating under natural vacuum have gained much interest. The present study is concerned with sea water desalination using natural vacuum technology.

The vapor pressure of saline water is less than that of fresh water. Consequently, if two columns are connected, one is filled with fresh water and the other is filled with saline water, under vacuum pressure and at ambient temperature, the generated vapor from the fresh water is then transported to the space above the saline water. Further, as the water temperature increases, the vapor pressure increases. Thus, exposing the column of the saline water to a heat source results in increasing its temperature and hence, increasing the vapor pressure of the saline water. Accordingly, the natural process can be reversed to get fresh water from saline water at low temperature.

The natural vacuum desalination technology (NVD) is still in the developing stages and the literature contains considerably few studies addressing different desalination systems operating under low pressure. AlKharabsheh and Goswami, [3] have experimentally studied a solar desalination system utilizing solar heat. Results showed that the daily output from this system could reach $6.5 \mathrm{l} / \mathrm{m}^{2}$ evaporator area, as compared to 3-4 $1 / \mathrm{m}^{2}$ from conventional flat basin solar still.

Gude et. al, [4] has developed a double-effect NVD system combined with the merits of multi effect desalination (MED) technology, which reuses the latent heat of vapor. The heat source temperature was $50{ }^{\circ} \mathrm{C}-70$ ${ }^{\circ} \mathrm{C}$. The double-effect NVD system has achieved a productivity of $0.349 \mathrm{l} / \mathrm{min}$ including $0.189 \mathrm{l} / \mathrm{min}$ from the first evaporator and $0.16 \mathrm{l} / \mathrm{min}$ from the second evaporator.

Gude et. al, [5] have studied a low temperature desalination system that produced $100 \mathrm{l} / \mathrm{d}$ of fresh water using a solar collector area of $15 \mathrm{~m}^{2}$ with $1 \mathrm{~m}^{3}$ of thermal energy storage (TES) volume.

Maroo and Goswami, [6] used the natural forces of gravity and atmospheric pressure to create a vacuum in single stage and two-stage systems. When coupled with a solar collector of $1 \mathrm{~m}^{2}$ area, a single stage system produced $0.71 \mathrm{l} / \mathrm{h}$, while the two-stage system produced $1.12 \mathrm{l} / \mathrm{hr}$. The obtained performance ratio was 0.748 and 1.35 for a single stage and two stage system respectively. The cost of water production by this method was found to be $3 \mathrm{USD} / \mathrm{m}^{3}$.

Teoman and Al Madani, [7] have studied natural vacuum desalination (NVD) with maximum temperature difference between seawater and ambient temperature of approximately $20{ }^{\circ} \mathrm{C}$. The pilot model of NVD system can supply distilled water at a production rate of $1.32 \mathrm{l} / \mathrm{h}$ with an evaporator diameter of $0.35 \mathrm{~m}$ and $10.79 \mathrm{l} / \mathrm{h}$ with a diameter of $1 \mathrm{~m}$.

Abutayeh and Goswami, [8, 9] have studied a passive vacuum flash desalination system. Numerical simulations have been carried out to examine the effect of flash temperature on performance of system. It has been concluded that, at a constant flash chamber volume, increasing the flash temperature leads to faster vacuum erosion, decreased run time, increased heater load, increased solar collection area, increased boiling point elevation, faster equilibrium attainment, and less overall evaporation. Increasing the flash temperature also increases the vacuum pressure which by definition reduces the vapor liquid equilibrium distribution coefficient of all non-condensable gases.

Ambarita and Himsar, [10] have studied experimentally and theoretically a natural vacuum desalination system at varying conditions. The performance of the natural vacuum desalination system was mainly affected by the maximum temperature in the evaporator and the minimum temperature in condenser. On the other hand, the surface area of heating coil and the heat recovery unit showed only a small effect.

More recently, Ambarita et. al, [11] have studied the phenomenon of evaporation-condensation in an evaporation chamber of natural vacuum solar desalination using CFD simulation. The CFD simulation was carried out on the gas mixture only. Mixture frame work with turbulence flow was used in the simulations.

The survey of the literature reveals that limited experimental investigations are reported for desalination systems using barometric head. Technical information available from these studies is not sufficient to develop a reliable low temperature desalination system for large or medium scale continuous operation. In this study, a new low temperature desalination system is designed, fabricated and assembled. The system feasibility is examined and an exhaustive experimental investigation is carried out to examine the performance under actual operating conditions.

\section{System Description and Operating Principles}

Figure 1 shows a schematic diagram of the experimental test set-up. The set-up consists mainly of the evaporator, the condenser, two storage tanks, and the necessary piping connections. The evaporator is designed similar to a liquid flat-plate solar collector as shown in Fig. 2. It is made from copper sheet of $0.5 \mathrm{~mm}$ thickness, $90 \mathrm{~cm}$ long and $90 \mathrm{~cm}$ width. It includes two headers of $1.9 \mathrm{~cm}$ diameter each, connected together with four riser tubes of $0.95 \mathrm{~cm}$ diameter. The whole assembly is placed in a wooden frame with $5 \mathrm{~cm}$ thermal insulation at the bottom and sides. A single glass cover is placed at the top. The evaporator is supported on a frame such that it makes a fixed tilt angle of 30 degrees to the horizontal. A sight glass tube is attached to the evaporator in order to indicate the water level inside the evaporator. The condenser consists of a $1.5 \mathrm{~mm}$ thick copper tube of 10.2 $\mathrm{cm}$ diameter and a length of $75 \mathrm{~cm}$ as shown in Fig. 3. Twelve longitudinal fins; $0.5 \mathrm{~mm}$ thickness and $3 \mathrm{~cm}$ height are fixed to the external surface of the condenser to increase the heat transfer area. A second sight glass tube is fixed on the side of the condenser in order to show the variation in water level inside the condenser and to provide an indication of the productivity. Two storage tanks are used in the set-up; one for the saline water and the other is for the fresh water. The condenser 
and the evaporator are kept at a height of 10 meters above ground level. The pipes connecting the evaporator and the condenser to the storage tanks are $2.5 \mathrm{~cm}$ diameter and are made of PVC. Ball valves are used to isolate the system sections where needed and an air vent is provided at the highest point in the set-up to vent out air when the system is being evacuated.

The test rig is equipped with suitable measuring devices. Transducers for measuring the components of solar radiation, the temperature at different positions, the vapor pressure inside the condenser, the water salinity, the wind speed and the fresh water productivity have been used. Solar radiation incident in the plane of the evaporator has been measured using Eppley PSP pyranometer ( $\pm \quad 0.5 \%$ accuracy). A shading ring arrangement has been used with the solar pyranometer for measuring the diffuse radiation while an Eppley pyrheliometer has been used to measure the beam radiation at normal incidence. Calibrated thermocouples of type $\mathrm{T}\left( \pm 1.5^{\circ} \mathrm{C}\right.$. accuracy) have been fixed at different positions as illustrated in Figures. (2) and (3). The vapor pressure is measured by using a vacuum pressure transducer having a range from 0 to 1 bar absolute $( \pm$ $0.1 \%$ accuracy). The productivity is calculated by measuring the difference of the water level in the condenser at a certain period of time, then, the accumulated water volume is calculated. The air velocity is measured with EXTECH Hydro Thermo-Anemometer ( $\pm 0.05 \%$ accuracy). The thermocouples and other sensors are connected to data acquisition system interfaced to a computer. The data acquisition system provides a cold junction compensation for temperature measurements and allows a variable scan rate starting from one sample per second. All sensors are scanned and recorded every minute and time averaging of 10 minutes has been programmed for all channels.

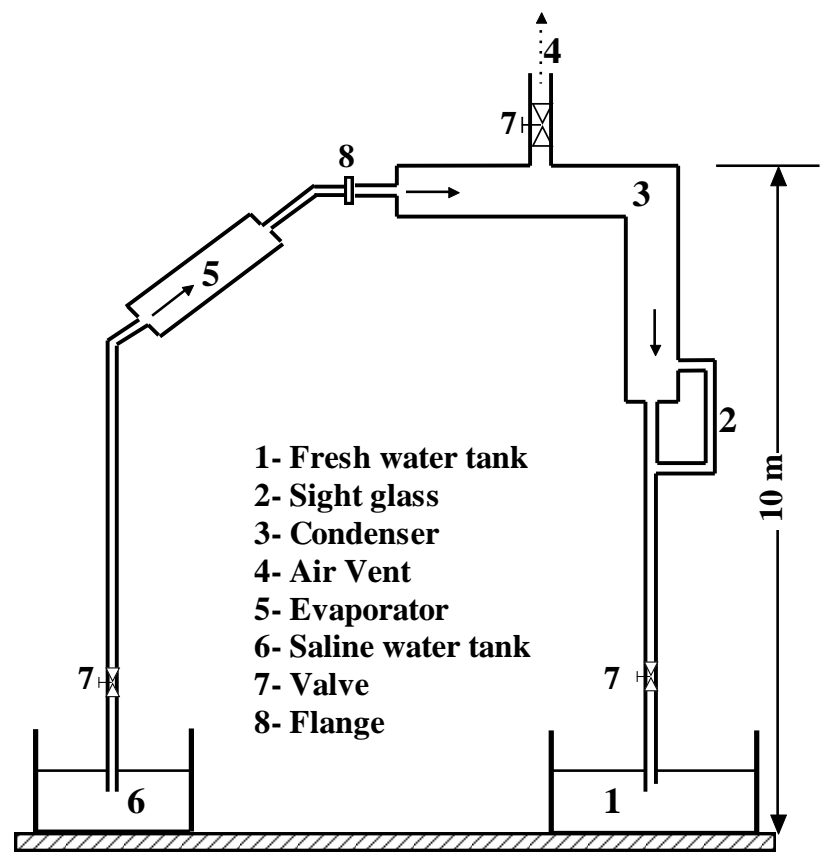

Fig. 1. Schematic Diagram of the Experimental Test Setup

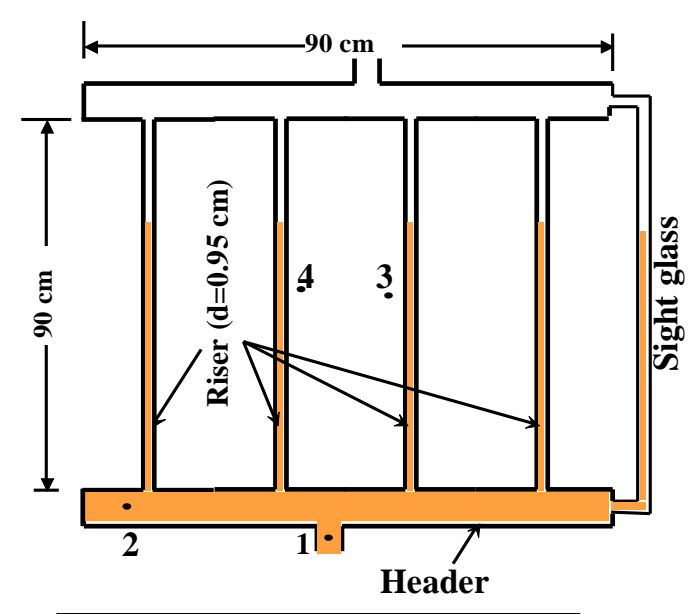

$$
\begin{aligned}
& \text { 1-inlet saline water temperature } \\
& \text { 2- saline water temperature } \\
& \text { 3-pipe surface temperature } \\
& \text { 4- absorber temperature }
\end{aligned}
$$

Fig. 2. Schematic Diagram of the Evaporator and Measurements Positions

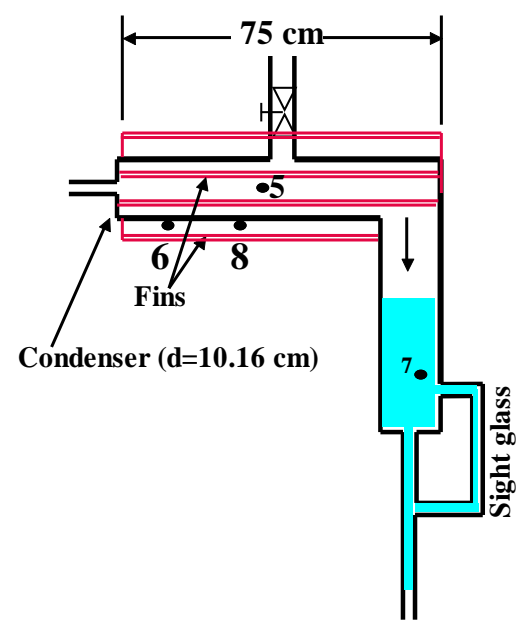
5 -vapour temperature
6- condenser surface temperature
7-fresh water temperature
8-pressure transducer

Fig. 3. Schematic Diagram of the condenser and Measurements Positions

To start up the system, it is filled up with water completely, and then the water is allowed to fall under the influence of gravity, in order to establish the vacuum. Depending on the barometric pressure, water will fall to a level of about $10 \mathrm{~m}$ from the ground level, leaving behind a vacuum space. The system has been checked for tightness and it has been observed that the system remains air tight for more than three continuous days 
before a degassing process is needed to remove the nondissolvable gases accumulated in the system components

\section{Results and Discussions}

Several experiments have been carried out to investigate the performance of the developed system under actual weather conditions. Each experiment has been conducted for a complete day to utilize the entire sunshine duration. The condenser has been cooled naturally using atmospheric air, forced convection and evaporative cooling. These cooling modes are chosen to minimize the initial cost of the system as well as the energy requirement. This part of the study is devoted to explaining the effect of the cooling rate of water on performance system and that is done by using continuous water pour on the surface of the condenser wrapped with a gunny bag cloth to ensure that the water is distributed homogenously on its surface throughout the day at

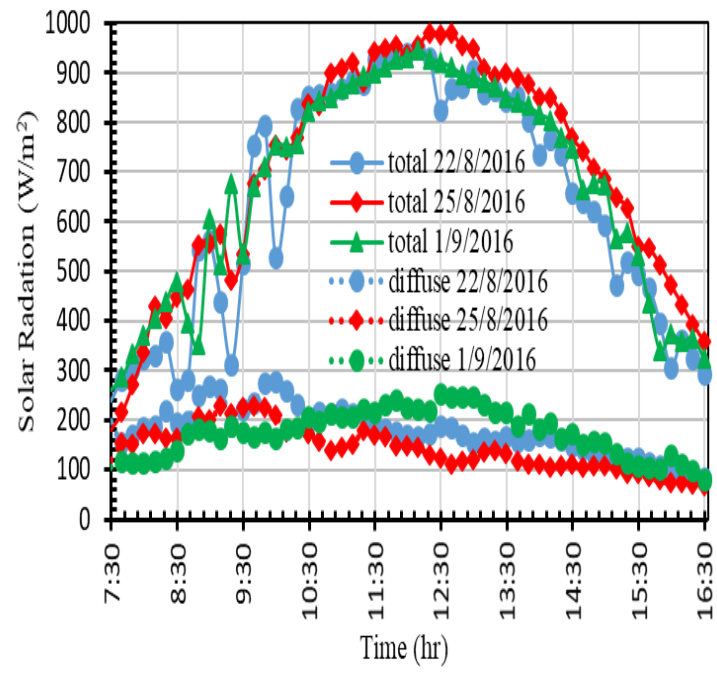

different flow rates. The results for using external water cooling of the condenser are reported in this section. Figure 4 presents the variation of solar radiation incident on the tilted surface of the evaporator at different days. The average of solar radiation for these days are 650 $\mathrm{W} / \mathrm{m}^{2}$. Some fluctuations are observed in morning and solar noon time, which may be attributed to presence of clouds. The ambient temperature of the three days is nearly the same.

The variation of the absorber temperature and the saline water temperature with time for different cooling water flowrates are shown in Fig. 5. It can be seen that the absorber temperature and saline water temperature are almost the same. The maximum absorber temperature is around $66{ }^{\circ} \mathrm{C}$. and that for saline water is $52{ }^{\circ} \mathrm{C}$. The variation of cooling water flow rate used for external cooling has a small affect the absorber and the saline water temperature.

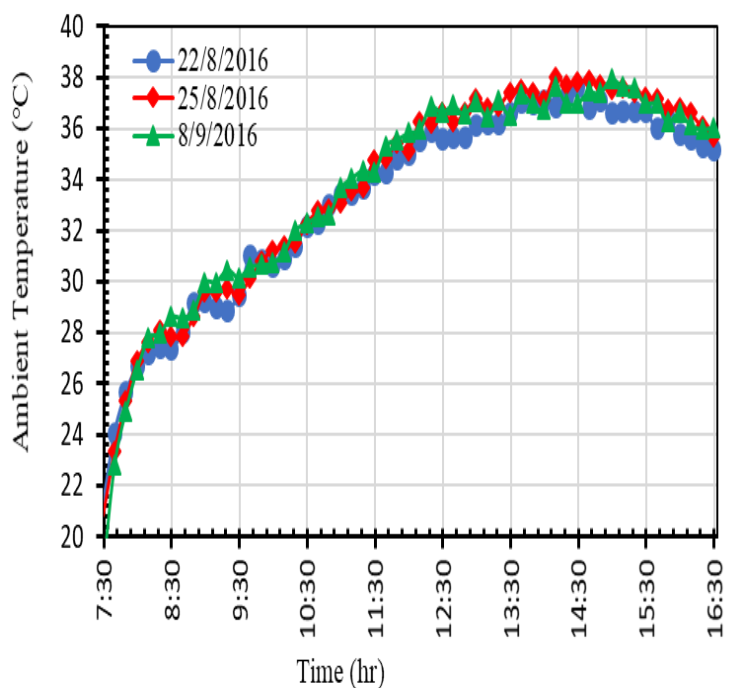

Fig. 4. Variation of Solar Radiation and Ambient Temperature with Time for three days
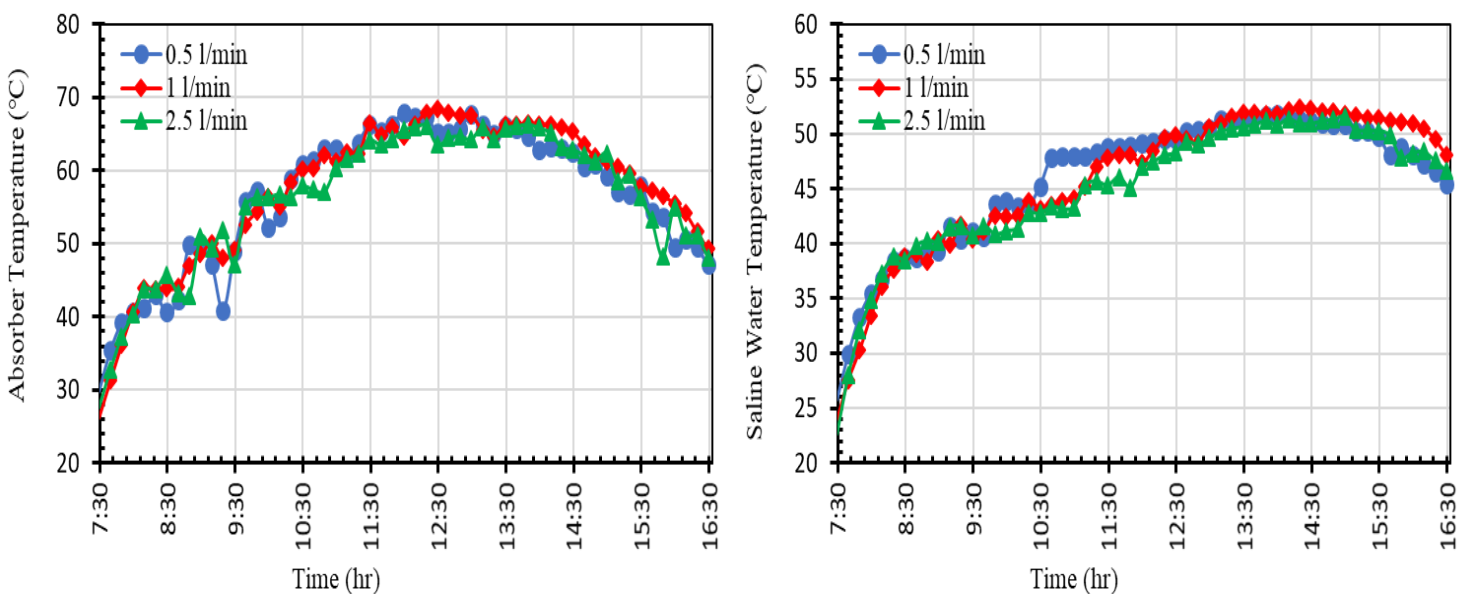

Fig. 5. Variation of Evaporator Temperatures with Time for Different Cooling Water Flowrates

The condenser surface temperature and vapour temperature are almost identical as shown in Fig. 6. which reflects the fact that the rate of water flow in external water cooled is not effective as the evaporation rate is equal to the condensation rate. The system pressure change is shown in Fig. 7. The pressure is 
nearly equal in the three cases because the vapour temperature for three cases is the same. The average of
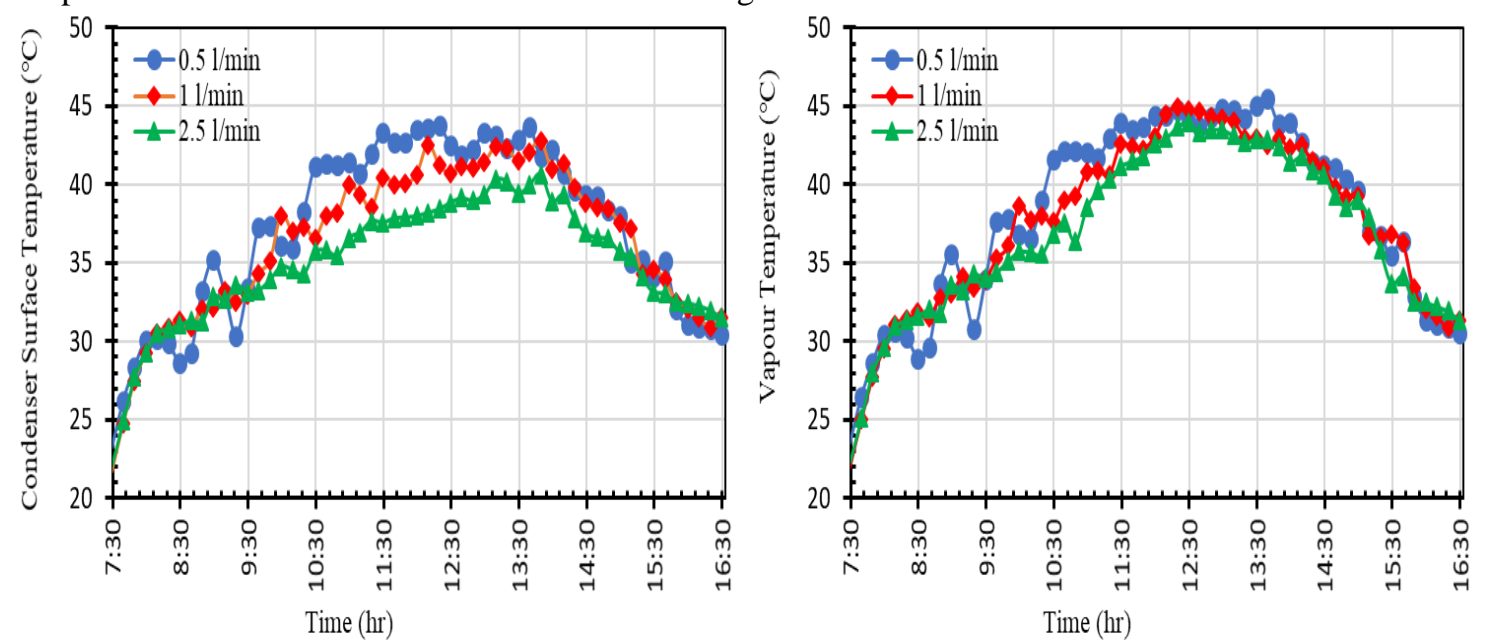

Fig. 6. Variation of Condenser and Vapour Temperatures with Time for Different Cooling Water Flowrates

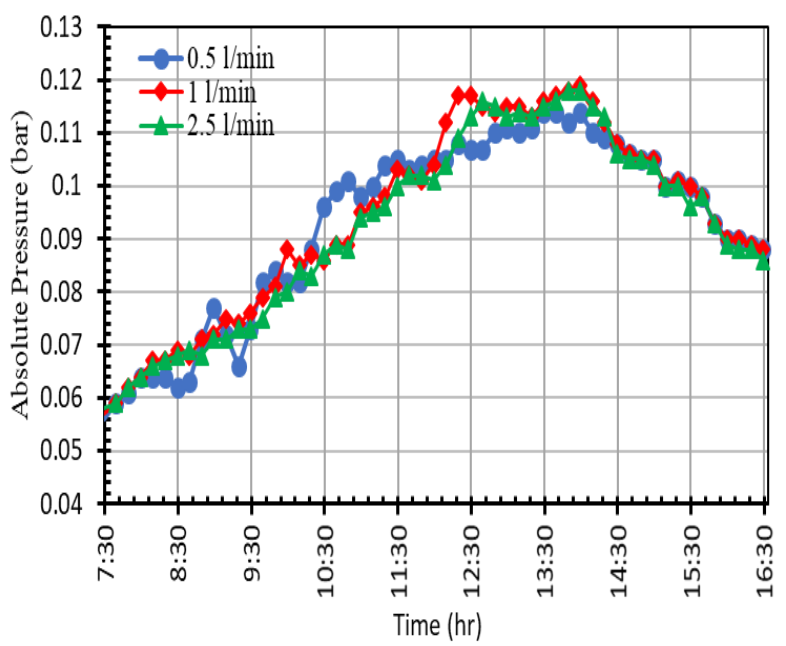

Fig. 7. Variation of System Pressure with Time for Different Cooling Water Flowrates

Figure 8 shows the variation in instantaneous and cumulative productivity. The average instantaneous productivity is around $640 \mathrm{ml} / \mathrm{h}$ for the three cases. The cumulative productivity for the three cases is around 6.8 $1 / \mathrm{m}^{2}$.day.The productivity of a new proposed system were $100 \%$ greater than that of the conventional basin type solar still for the same area [12].

The system performance ratio (PR) has been used to assess the performance of the desalination process. The performance ratio is defined as

$$
P R=\frac{\dot{m}_{e v} h_{f g\left(T_{\text {saline water }}\right)}}{I_{T} A}
$$

Where $\dot{m}_{e v}$ is the mass flowrate of distillate $(\mathrm{kg} / \mathrm{s}), \mathrm{h}_{\mathrm{fg}}$ is the latent heat of vaporization $(\mathrm{kJ} / \mathrm{kg})$ at the saline water temperature $(T), I_{T}$ is total solar radiation $\left(\mathrm{W} / \mathrm{m}^{2}\right)$, and $\mathrm{A}$ is the collection area $\left(\mathrm{m}^{2}\right)$.

Figure 9 shows the variation of performance ratio with time for different cooling water flowrate. The average performance ratio is around $70 \%$ for the three cases. The performance ratio of the proposed system was $100 \%$ greater than that of the conventional basin type solar still for the same area. From the above discussion the case of $0.5 \mathrm{l} / \mathrm{min}$ of water flow rate is enough to get the maximum productivity of fresh water. 

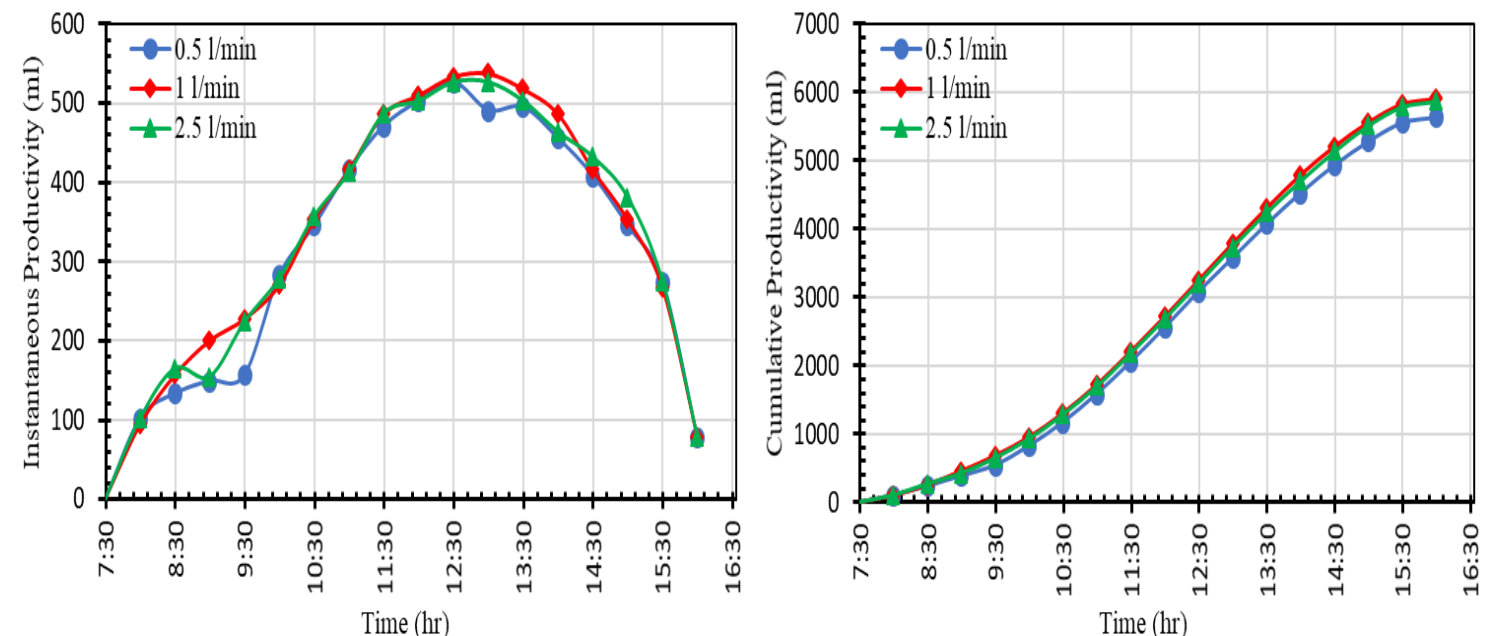

Fig. 8. Variation of Hourly and cumulative Productivity with Time for Different Cooling Water Flowrates

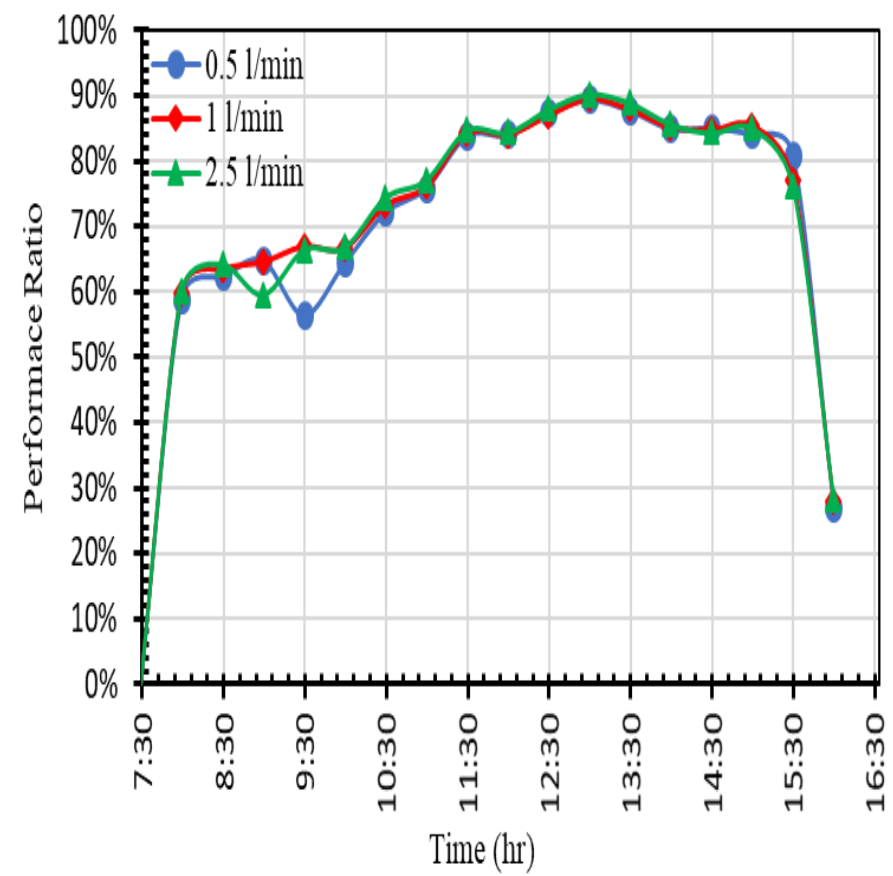

Fig. 9. Variation of the Performance Ratio with Time for Different Cooling Water Flowrates

In the following figures, a comparison for the effect of the three modes of cooling the condenser on the system performance is shown. The cooling modes are free convection, forced convection with air velocity at $4 \mathrm{~m} / \mathrm{s}$ and external water cooled condenser at $0.5 \mathrm{l} / \mathrm{m}$ water flow rate.
The atmospheric conditions are nearly identical except for the early morning hours where few fluctuations in solar radiation are experienced as seen from Fig. 10

The absorber temperature in the three cases are very close to one another as illustrated in Fig. 11. and the maximum value is around $69{ }^{\circ} \mathrm{C}$ at solar noon. 

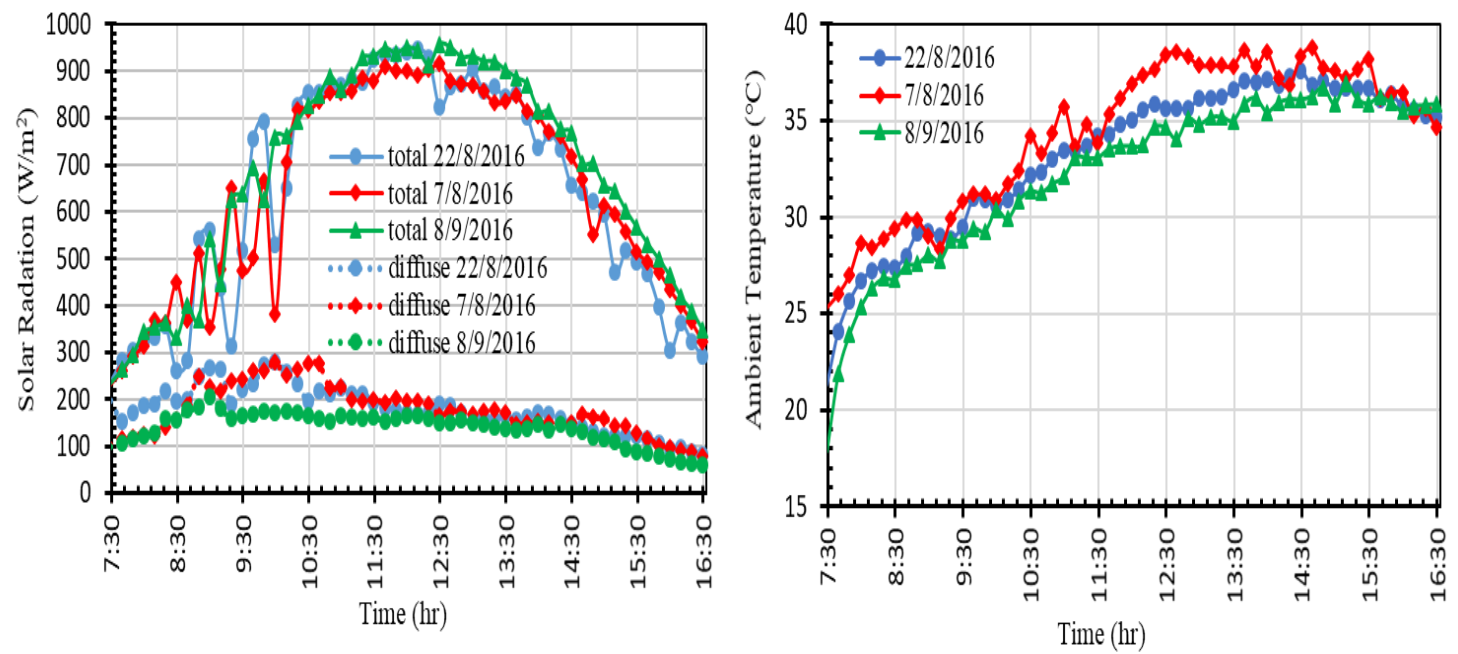

Fig. 10. Variation of Solar Radiation and Ambient Temperature with Time

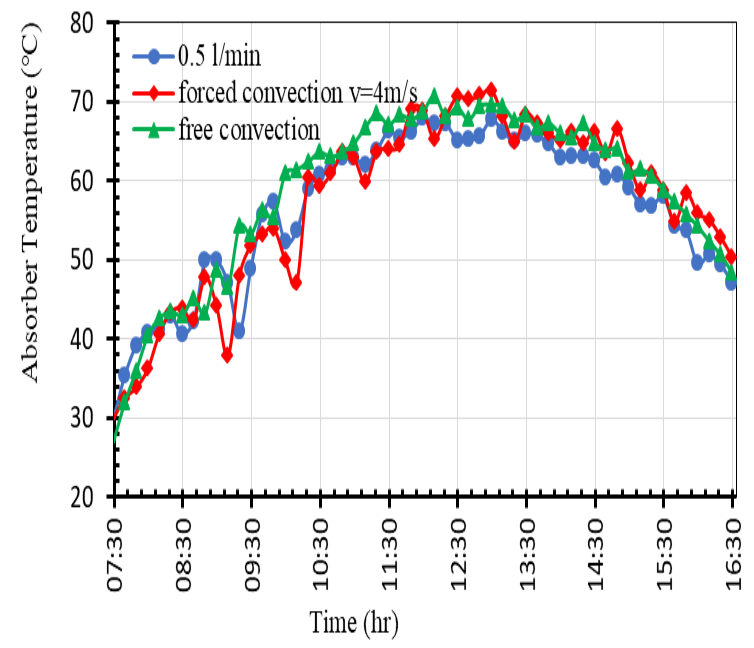

Fig. 11. Effect of Condenser Cooling Mode on Absorber Temperature

The temperature difference between saline water and condenser surface temperature in the three cases (free convection, forced convection and external water cooled) increases with increase in cooling rate. The corresponding values were 4,6 and $8{ }^{\circ} \mathrm{C}$ respectively as shown in Fig. 12. This led to a pressure difference between the evaporator and the condenser, which causes acceleration to the vapour movement which results in an increase in the condensation rate. The vapour and fresh water temperatures show lower values in the case of external water cooled, leading to a conclusion that external water cooled mode is better method of cooling among the methods attempted in this study.

The effect of cooling mode on the system pressure is shown in Fig. 13. From this figure it can be noted that, the cooling mode has a consederable effect on the system pressure due to the difference in the vapour and condenser surface temperature. 

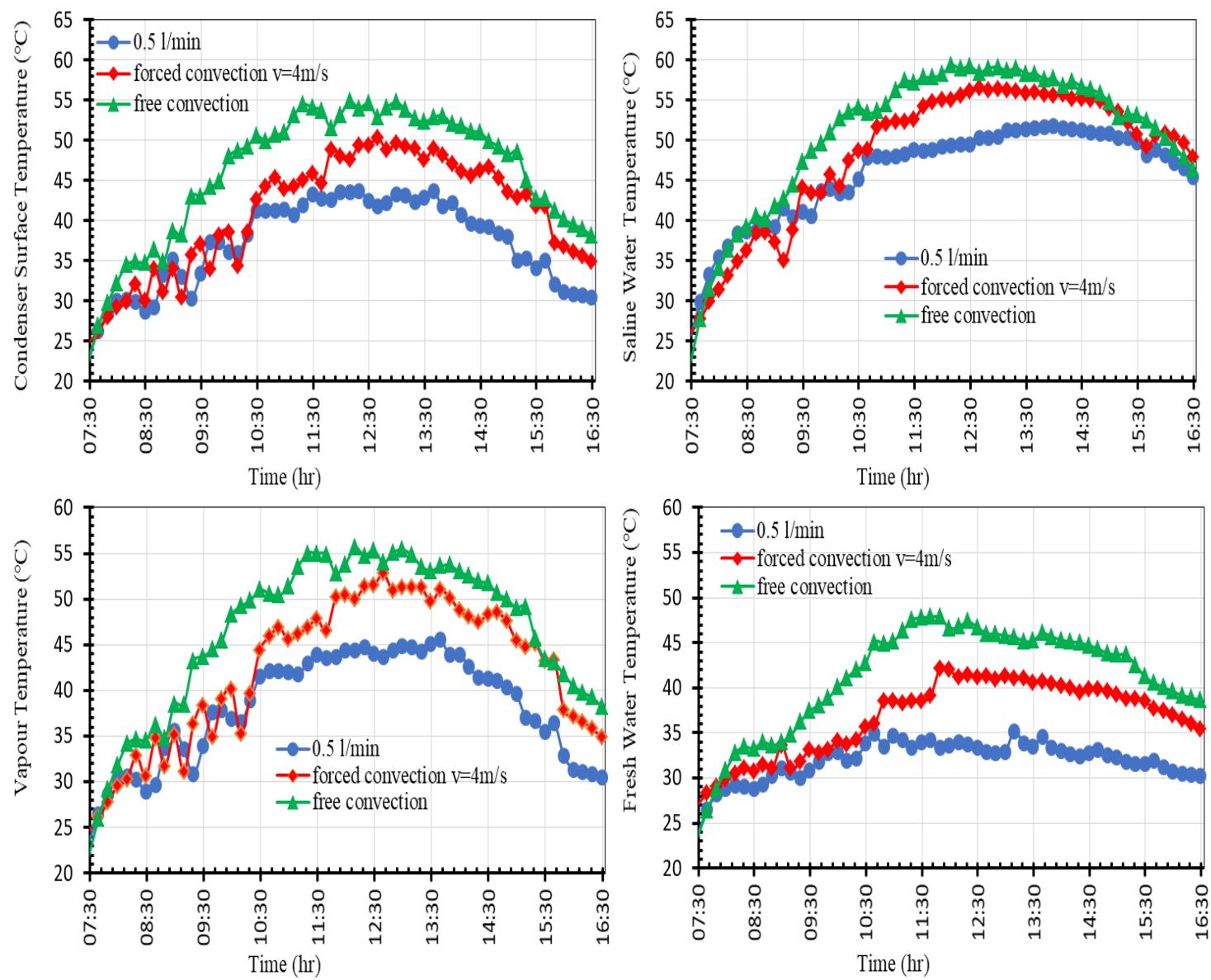

Fig. 12. Effect of Condenser Cooling Mode on System Temperatures

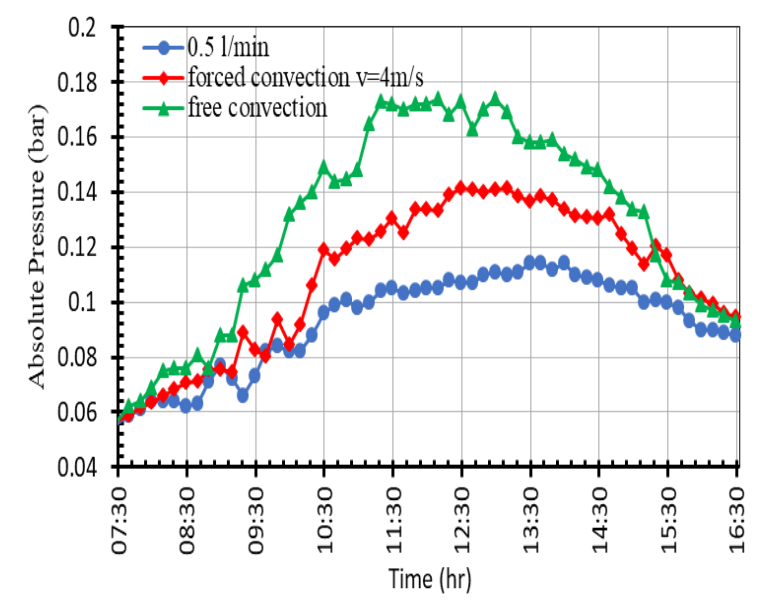

Fig. 13. Effect of Condenser Cooling Mode on system Pressure

Figure 14 shows that the instantaneous productivity, obtained in the three cases, are close to one another in the morning then the difference starts to increase and reaches maximum values at solar noon around 526,416 , $180 \mathrm{ml}$ every half an hour $(1052,832$ and $360 \mathrm{ml} / \mathrm{h})$ for external water cooled, forced convection and free convection respectively. The cumulative productivity is maximum in the case of external water cooled reaching a value of $6.6 \mathrm{1} / \mathrm{m}^{2}$.day which is higher than forced and free convection which yielded values of 5.3 and 2.7 $1 / \mathrm{m}^{2}$.day respectively. This difference in cumulative productivity as in external water cooled as it had the lowest condenser pressure. The average performance ratio is maximum in the case of external water cooled reaching a value of $70 \%$ which is higher than forced and free convection whose values were $54 \%$ and $28 \%$ respectively as shown in Fig.15. From the above study, the best cooling mechanism is the external water cooled as it achieves the highest performance ratio with an average value of $70 \%$ which is more than twice of that of the solar still. 

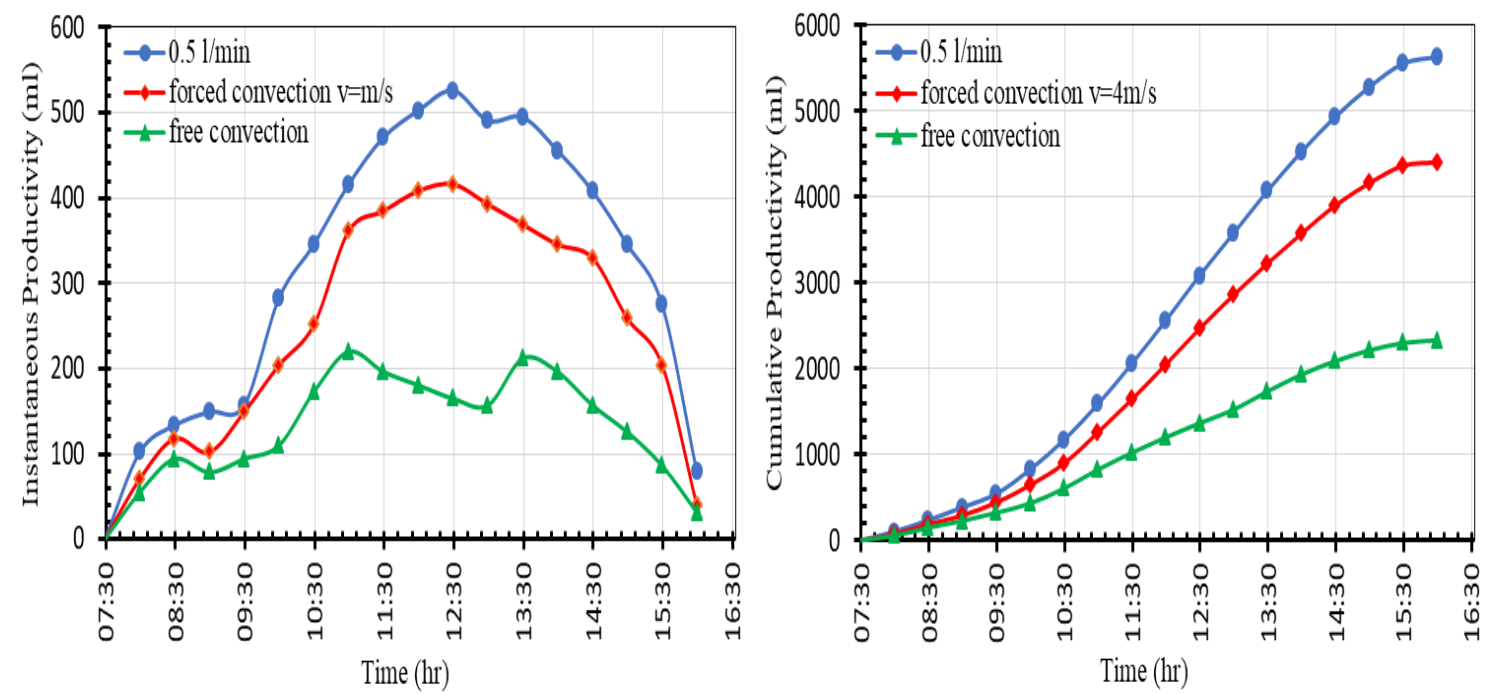

Fig. 14. Effect of Condenser Cooling Mode on Fresh Water Output.

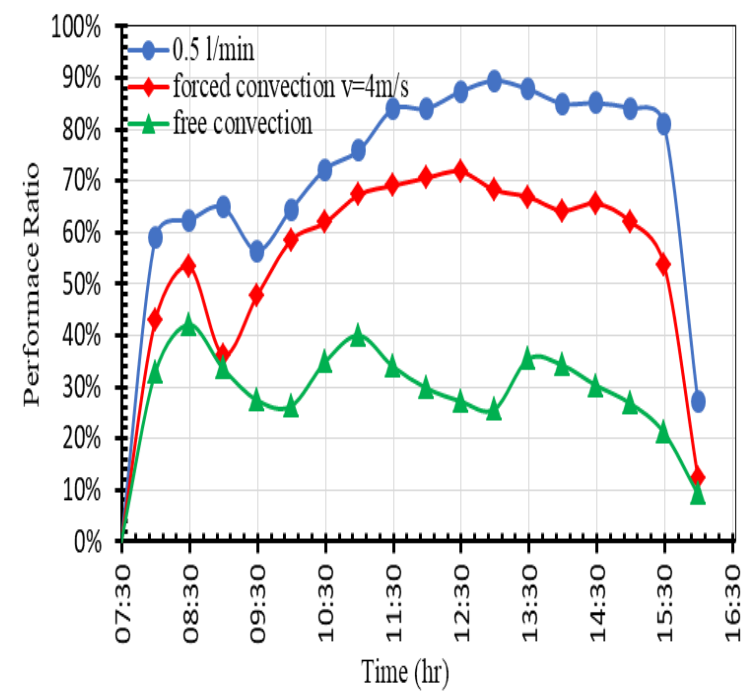

Fig. 15. Effect of Condenser Cooling Mode on Performance Ratio. 


\section{CONCLUSIONS}

A novel natural vacuum desalination system has been proposed. The system has been fabricated, assembled and equipped with necessary measuring devices. An extensive experimental investigation has been carried out to examine the technical feasibility of the system. The system makes use of natural forces of gravity and atmospheric pressure to create a vacuum under which water can be evaporated more rapidly at low temperatures. The system has been operated under actual weather conditions using natural air cooling, forced convection and external cooling for the condenser. The hourly and the cumulative productivity have been measured. From the obtained results, the following major concluding points can be drawn:

1. The proposed system can achieve a natural vacuum between 0.09 to 0.122 bars absolute depending on the mode of cooling, and can produce fresh water at a relatively low temperature ranging between 44 to $49^{\circ} \mathrm{C}$

2. The system is able to produce potable water at a daily rate of $6.6 \mathrm{liter} / \mathrm{m}^{2}$ when water cooling is employed, which is more than twice of that of the solar still for the same area, [12], and about $2.7 \mathrm{liter} / \mathrm{m}^{2}$ every day when cooled naturally by atmospheric air.

3. The performance ratio of the system is as high as $70 \%$ using water cooling and reaches an average value of about $28 \%$ using natural air cooling mode.

4. The flow rate of condenser cooling water has been experimented upon and a coolant flow rate of 0.5 liters/min was found as an optimum value for best operation of the system. The system performance under such conditions was found competitive to other desalination systems utilizing conventional techniques.

\section{REFERENCES}

$1-$

Al-Kharabsheh, Saleh A., "Theoretical and experimental analysis of water desalination system using low grade solar heat", PhD dissertation., University of Florida, 2003.

2- Kalogirou, Soteris, "Economic analysis of a solar assisted desalination system" Renewable energy Vol. 12(4), 1997, PP. 351-367.

3- $\quad$ Al-Kharabsheh, S., and D. Yogi, "Analysis of an innovative water desalination system using low-grade solar heat", Desalination, Vol. 156, 2003, PP.323-332.

4- Gude, Veera Gnaneswar, Nagamany Nirmalakhandan, Shuguang Deng, Anand Magantid, "Feasibility study of a new two-stage low temperature desalination process", Energy Conversion and Management, Vol. 56, 2012, PP. 192-198.

5- Gude, Veera Gnaneswar, Nagamany Nirmalakhandan, Shuguang Deng, Anand Magantid, "Low temperature desalination using solar collectors augmented by thermal energy storage", Applied Energy, Vol. 91, 2012, PP. 466-474.

6- Maroo, Shalabh C., and D. Yogi Goswami, "Theoretical analysis of a single-stage and two-stage solar driven flash desalination system based on passive vacuum generation", Desalination, Vol. 249, 2009, PP. 635-646.

7- Ayhan, Teoman, and Hussain Al Madani, "Feasibilty study of renewable energy powered seawater desalination technology using natural vacuum technique", Renewable energy Vol. 35, 2010, PP. 506514.

8- Abutayeh, Mohammad, and D. Yogi Goswami, "Solar flash desalination under hydrostatically sustained vacuum", Journal of Solar Energy Engineering, Vol.131, 2009, PP. 031016.

9- Abutayeh, Mohammad, and D. Yogi Goswami, "Passive vacuum solar flash desalination", AIChE journal, Vol. 56, 2010, PP. 1196-1203.

10- Ambarita, Himsar. "Study on the performance of natural vacuum desalination system using low grade heat source", Case Studies in Thermal Engineering, Vol. 8, 2016, PP. 346-358.

11- Ambarita, H., A D Ronowikarto, R E T Siregar and E Y Setyawan., "CFD Analysis of EvaporationCondensation Phenomenon in an Evaporation Chamber of Natural Vacuum Solar Desalination", IOP Conference Series: Materials Science and Engineering, Vol, 300. No. $1,2018$.

12- Farahat, M. A., M. M. Mousa, and N. H. Mahmoud, "Solar Distiller with Flat Plate Collector and Thermal storage", Proceedings of the 17th Int. AMME Conference, Vol. 19, 2016. 